Acta Crystallographica Section C

Crystal Structure

Communications

ISSN 0108-2701

\section{Glyoxal 4-nitrophenylhydrazone: triple helices linked into a three- dimensional channel structure}

\author{
Christopher Glidewell, ${ }^{a *}$ John N. Low, ${ }^{b}$ Janet M. S. \\ Skakle $^{\mathrm{b}}$ and James L. Wardell ${ }^{\mathrm{c}}$
}

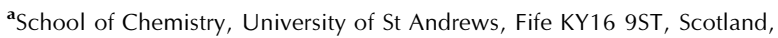
${ }^{\mathbf{b}}$ Department of Chemistry, University of Aberdeen, Meston Walk, Old Aberdeen AB24 3UE, Scotland, and ' Instituto de Química, Departamento de Química Inorgânica, Universidade Federal do Rio de Janeiro, 21945-970 Rio de Janeiro, RJ, Brazil

Correspondence e-mail: cg@st-andrews.ac.uk

Received 28 June 2005

Accepted 30 June 2005

Online 23 July 2005

The molecules of the title compound, $\mathrm{C}_{8} \mathrm{H}_{7} \mathrm{~N}_{3} \mathrm{O}_{3}$, which are nearly planar, are linked by an $\mathrm{N}-\mathrm{H} \cdots \mathrm{O}$ hydrogen bond into helical chains, three of which are required to define the structure completely. These triply intertwined helices are linked by a $\mathrm{C}-\mathrm{H} \cdots \mathrm{O}$ hydrogen bond into a three-dimensional framework enclosing two distinct types of channel, with average cross-sectional areas of 15.0 and $8.2 \AA^{2}$.

\section{Comment}

The title compound, (I), was prepared as part of our continuing study of the supramolecular arrangements of $\mathrm{N}$-(nitrophenyl)imide and -hydrazone derivatives.

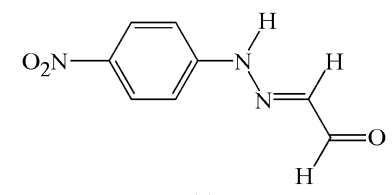

(I)

The molecules of compound (I) (Fig. 1) are almost planar, as shown by the leading torsion angles (Table 1). The side chain between atoms $\mathrm{N} 1$ and $\mathrm{O} 1$ adopts a planar all-trans conformation, and the nitro group is nearly coplanar with the aryl ring. The bond distances in the 4-nitrophenylhydrazone fragment provide no evidence for the occurrence of the type of quinonoid bond fixation found in 4-nitroaniline (Tonogaki et al., 1993), which is also typical of simple substituted 4-nitroanilines (Cannon et al., 2001; Ferguson et al., 2001; Glidewell et al., 2001, 2002, 2004). There is strong bond fixation in the side chain, with very short $\mathrm{N} 2-\mathrm{C} 11$ and $\mathrm{C} 12-\mathrm{O} 1$ bonds, with no evidence for bond polarization in this fragment.

The supramolecular structure of (I) is three-dimensional and of considerable complexity, but it is constructed using only two hydrogen bonds, one each of the $\mathrm{N}-\mathrm{H} \cdots \mathrm{O}$ and $\mathrm{C}-$
$\mathrm{H}$. . O types (Table 2). The hydrazine atom N1 in the molecule at $(x, y, z)$ acts as hydrogen-bond donor to aldehyde atom $\mathrm{O} 1$ in the molecule at $\left(\frac{3}{4}-y, \frac{1}{4}+x, z-\frac{3}{4}\right)$, while atom $\mathrm{N} 1$ at $\left(\frac{3}{4}-y\right.$, $\left.\frac{1}{4}+x, z-\frac{3}{4}\right)$ in turn acts as donor to atom $\mathrm{O} 1$ at $\left(\frac{1}{2}-x, 1-y\right.$, $\left.z-\frac{3}{2}\right)$, and thence via the molecule at $\left(y-\frac{1}{4}, \frac{3}{4}-x, z-\frac{9}{4}\right)$ to that at $(x, y, z-3)$. In this way, a $C(6)$ helical chain is formed running parallel to the [001] direction and generated by the $4_{1}$ screw axis along $\left(\frac{1}{4}, \frac{1}{2}, z\right)$. One complete turn of this helix spans three unit cells along [001], linking the molecule at $(x, y, z)$ with those at $(x, y, n+z)(n=$ positive or negative integer). Hence, completion of the structure requires three such helical chains, offset by unit translations along [001]. Thus, the effect of the $\mathrm{N}-\mathrm{H}$. . O hydrogen bond is the generation of triply intertwined helices (Fig. 2). There are no direction-specific interactions between the independent helices in each set of three helices.

The effect of the $\mathrm{C}-\mathrm{H} \cdots \mathrm{O}$ hydrogen bond is to link the helices into a three-dimensional framework. Aldehyde atom $\mathrm{C} 12$ in the molecule at $(x, y, z)$ acts as hydrogen-bond donor to nitro atom $\mathrm{O} 41$ in the molecule at $(1-x, 1-y, 2-z)$, so generating a centrosymmetric $R_{2}^{2}(22)$ motif centred at $\left(\frac{1}{2}, \frac{1}{2}, 1\right)$ (Fig. 3). The two molecules in this motif form parts of helices along $\left(\frac{1}{4}, \frac{1}{2}, z\right)$ and $\left(\frac{3}{4}, \frac{1}{2},-z\right)$, generated by $4_{1}$ and $4_{3}$ axes, respectively, and propagation of this dimer motif thus links the

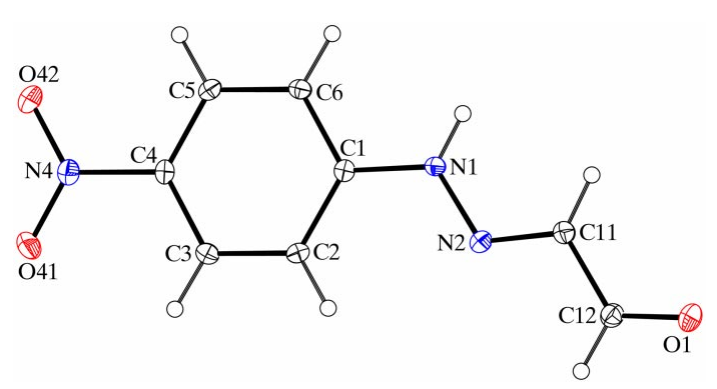

Figure 1

The molecule of (I), showing the atom-labelling scheme. Displacement ellipsoids are drawn at the $30 \%$ probability level.

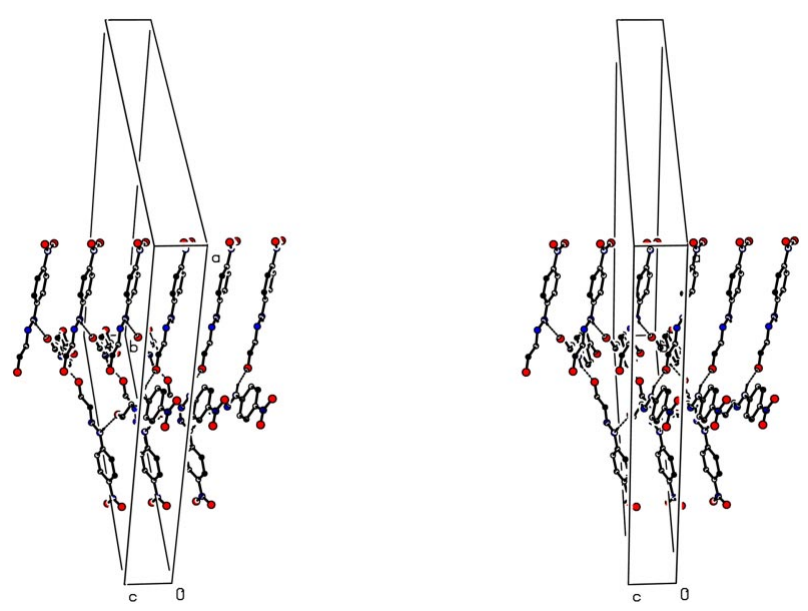

Figure 2

A stereoview of part of the crystal structure of (I), showing the formation of triply intertwined $C(6)$ helices along $\left(\frac{1}{4}, \frac{1}{2}, z\right)$. For the sake of clarity, $\mathrm{H}$ atoms bonded to $\mathrm{C}$ atoms have been omitted. 
reference helix along $\left(\frac{1}{4}, \frac{1}{2}, z\right)$ to the four adjacent helices along $\left(\frac{3}{4}, \frac{1}{2},-z\right),\left(\frac{1}{4}, 0,-z\right),\left(-\frac{1}{4}, \frac{1}{2},-z\right)$ and $\left(\frac{1}{4}, 1,-z\right)$, all of which are of opposite hand to the reference helix. In this way, the helices are linked into a three-dimensional framework (Fig. 4), more strictly described as three interwoven frameworks.

Within the framework there are channels running parallel to the [001] direction and accounting in total for $340.1 \AA^{3}$ per unit cell, i.e. some $9.4 \%$ of the total volume. This volume is, in fact, partitioned between two types of channel, with four of each type per cell. The larger channels lie along the $\overline{4}$ axes, with an average cross-sectional area of $c a 15.0 \AA^{2}$ and an average diameter of $c a 4.4 \AA$, while the smaller channels lie along the $4_{1}$ and $4_{3}$ axes and have an average cross-sectional area of $c a 8.2 \AA^{2}$ and an average diameter of $c a 3.2 \AA$. There is evidence for a very low population of water molecules, possibly disordered and/or mobile, within the larger channels, but no tractable refinement of these guest molecules proved

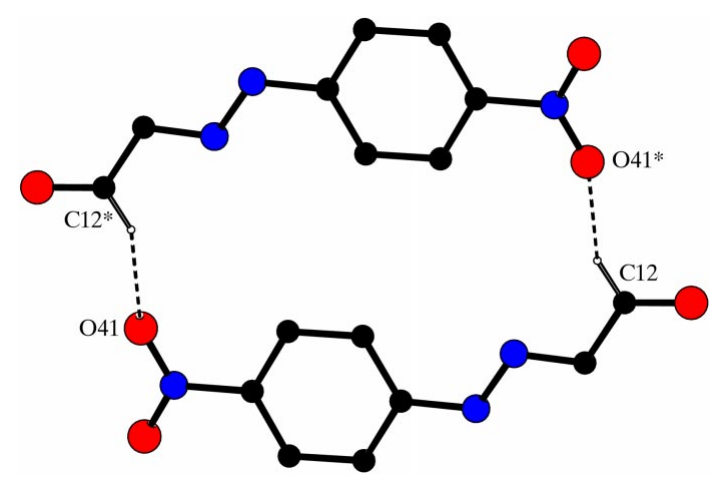

Figure 3

Part of the crystal structure of (I), showing the formation of a centrosymmetric $R_{2}^{2}(22)$ ring. For the sake of clarity, $\mathrm{H}$ atoms not involved in the motif shown have been omitted, as has the unit-cell outline. Atoms marked with an asterisk $(*)$ are at the symmetry position $(1-x, 1-y, 2-z)$.

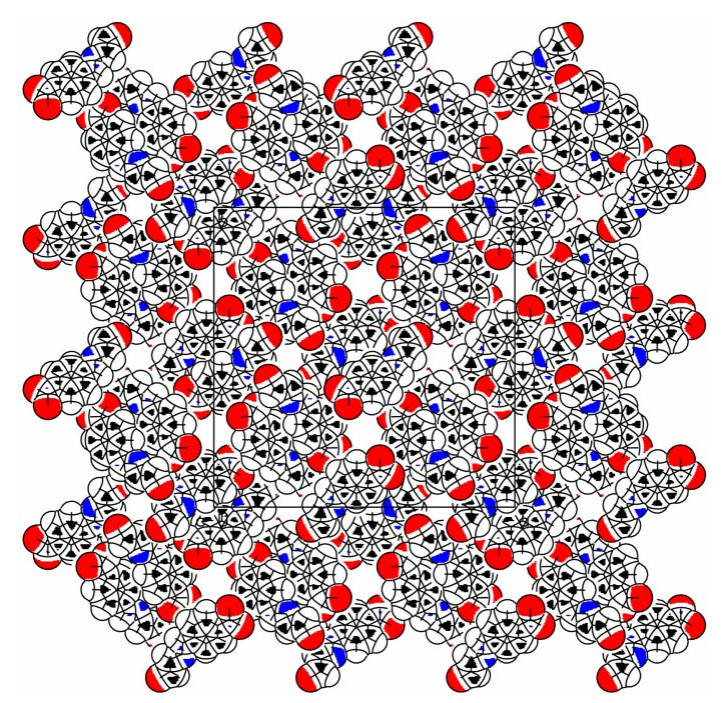

Figure 4

A space-filling projection, down [001], of part of the crystal structure of (I), showing the formation of the three-dimensional framework enclosing two types of channel along [001].

possible. It is not clear whether this residual water is a byproduct of the preparation or whether it had been absorbed from the atmosphere after crystallization.

The larger channels in (I) are thus of very similar diameter to those found in piperazine-4,4'-sulfonyldiphenol (1/2) (Coupar et al., 1996), where the channels of diameter $4.3 \AA$ are entirely unoccupied. In the channel structures formed by $N, N^{\prime}$ dithiobisphthalimide (Skakle et al., 2001; Farrell et al., 2002; Bowes, Ferguson, Glidewell, Lough et al., 2002; Bowes, Ferguson, Glidewell, Low \& Quesada, 2002), the channels are a little larger, with average cross-sectional areas of $c a 20.4 \AA^{2}$ and average diameters of $c a 5.1 \AA$. The channels in $N, N^{\prime}$ dithiobisphthalimide are always occupied by guest molecules, but the behaviour of the guest can vary from full ordering, as for $p$-xylene, to intractable disorder of probably mobile molecules for guests such as dichloromethane or tetrahydrofuran.

\section{Experimental}

Compound (I) was prepared by heating under reflux for $1 \mathrm{~h}$ a solution of glyoxal ( $1 \mathrm{mmol}$ as a $40 \%$ aqueous solution) and 4-nitrophenylhydrazine $(1 \mathrm{mmol})$ in methanol $(40 \mathrm{ml})$. The mixture was cooled to ambient temperature and the solvent removed under reduced pressure. The residue was crystallized from ethanol to yield crystals of (I) suitable for single-crystal X-ray diffraction. IR ( $\mathrm{KBr}$ disk, $v, \mathrm{~cm}^{-1}$ ): 3263-2850, 1698 (sh), 1686, 1677 (sh), 1538, 1504, 1331, 1272, 1131, 894, 839, 748, 690, 609, 489, 447.

\section{Crystal data}

$\mathrm{C}_{8} \mathrm{H}_{7} \mathrm{~N}_{3} \mathrm{O}_{3}$

$M_{r}=193.17$

Tetragonal, $I 4_{1} / a$

$a=31.4722(12) \AA$

$c=3.65600(10) \AA$

$V=3621.3(2) \AA^{3}$

$Z=16$

$D_{x}=1.417 \mathrm{Mg} \mathrm{m}^{-3}$

\author{
Mo $K \alpha$ radiation \\ Cell parameters from 2066 \\ reflections \\ $\theta=4.1-27.5^{\circ}$ \\ $\mu=0.11 \mathrm{~mm}^{-1}$ \\ $T=120(2) \mathrm{K}$ \\ Rod, red \\ $0.32 \times 0.08 \times 0.06 \mathrm{~mm}$
}

\section{Data collection}

Bruker-Nonius KappaCCD areadetector diffractometer

$\varphi$ and $\omega$ scans

Absorption correction: multi-scan (SADABS; Sheldrick, 2003)

$T_{\min }=0.974, T_{\max }=0.993$

2068 measured reflections

\section{Refinement}

Refinement on $F^{2}$

$R\left[F^{2}>2 \sigma\left(F^{2}\right)\right]=0.037$

$w R\left(F^{2}\right)=0.098$

$S=1.06$

2066 reflections

127 parameters

$\mathrm{H}$-atom parameters constrained

Table 1

Selected geometric parameters $\left(\AA{ }^{\circ}{ }^{\circ}\right)$.

\begin{tabular}{lrlr}
\hline $\mathrm{C} 1-\mathrm{N} 1$ & $1.3889(16)$ & $\mathrm{C} 11-\mathrm{C} 12$ & $1.4451(18)$ \\
$\mathrm{N} 1-\mathrm{N} 2$ & $1.3319(14)$ & $\mathrm{C} 12-\mathrm{O} 1$ & $1.2214(15)$ \\
$\mathrm{N} 2-\mathrm{C} 11$ & $1.2995(16)$ & & \\
$\mathrm{C} 2-\mathrm{C} 1-\mathrm{N} 1-\mathrm{N} 2$ & $0.20(18)$ & $\mathrm{C} 3-\mathrm{C} 4-\mathrm{N} 4-\mathrm{O} 41$ & $-3.42(18)$ \\
$\mathrm{C} 1-\mathrm{N} 1-\mathrm{N} 2-\mathrm{C} 11$ & $-176.38(11)$ & $\mathrm{C} 3-\mathrm{C} 4-\mathrm{N} 4-\mathrm{O} 42$ & $174.96(12)$ \\
$\mathrm{N} 1-\mathrm{N} 2-\mathrm{C} 11-\mathrm{C} 12$ & $-179.62(11)$ & $\mathrm{C} 5-\mathrm{C} 4-\mathrm{N} 4-\mathrm{O} 41$ & $178.35(12)$ \\
$\mathrm{N} 2-\mathrm{C} 11-\mathrm{C} 12-\mathrm{O} 1$ & $-179.34(13)$ & $\mathrm{C} 5-\mathrm{C} 4-\mathrm{N} 4-\mathrm{O} 42$ & $-3.27(18)$ \\
\hline
\end{tabular}

2066 independent reflections 1712 reflections with $I>2 \sigma(I)$ $R_{\text {int }}=0.039$

$\theta_{\text {max }}=27.5^{\circ}$

$h=-27 \rightarrow 28$

$k=0 \rightarrow 40$

$l=0 \rightarrow 4$

$$
\begin{aligned}
& w=1 /\left[\sigma^{2}\left(F_{\mathrm{o}}^{2}\right)+(0.0445 P)^{2}\right. \\
& \quad+2.7428 P] \\
& \text { where } P=\left(F_{\mathrm{o}}{ }^{2}+2 F_{\mathrm{c}}{ }^{2}\right) / 3 \\
& (\Delta / \sigma)_{\max }=0.001 \\
& \Delta \rho_{\max }=0.21 \mathrm{e} \AA^{-3} \\
& \Delta \rho_{\min }=-0.21 \mathrm{e}^{-3}
\end{aligned}
$$


Table 2

Hydrogen-bond geometry $\left(\AA,^{\circ}\right)$.

\begin{tabular}{lllll}
\hline$D-\mathrm{H} \cdots A$ & $D-\mathrm{H}$ & $\mathrm{H} \cdots A$ & $D \cdots A$ & $D-\mathrm{H} \cdots A$ \\
\hline $\mathrm{N} 1-\mathrm{H} 1 \cdots \mathrm{O} 1{ }^{\mathrm{i}}$ & 0.88 & 2.03 & $2.8574(14)$ & 155 \\
$\mathrm{C} 12-\mathrm{H} 12 \cdots \mathrm{O} 41^{\mathrm{ii}}$ & 0.95 & 2.46 & $3.2851(17)$ & 145
\end{tabular}

Symmetry codes: (i) $\frac{3}{4}-y, x+\frac{1}{4}, z-\frac{3}{4}$; (ii) $1-x, 1-y, 2-z$.

Crystals of compound (I) are tetragonal. The unit cell has a markedly tabular shape, with an axial $c / a$ ratio of only 0.116 . The space group $I 4_{1} / a$ was uniquely assigned from the systematic absences, and the origin was set to lie at an inversion centre. All $\mathrm{H}$ atoms were located from difference maps and then treated as riding atoms, with $\mathrm{C}-\mathrm{H}$ distances of $0.95 \AA$ and $\mathrm{N}-\mathrm{H}$ distances of $0.88 \AA$, and with $U_{\text {iso }}(\mathrm{H})=1.2 U_{\text {eq }}(\mathrm{C}, \mathrm{N})$. Examination of the refined structure using PLATON (Spek, 2003) revealed the presence of void spaces having a total volume of $340.1 \AA^{3}$ per unit cell, arranged into a series of channels running parallel to the [001] direction. There was a low residual electron density of $0.9 \mathrm{e} \AA^{-3}$ located on a $\overline{4}$ axis within the larger of the channels, which is most plausibly ascribed to a partial water molecule. When this density was assigned to an $\mathrm{O}$ atom and its site occupancy refined, with $U_{\text {iso }}(\mathrm{O})$ fixed at $0.03 \AA^{2}$, the occupancy refined to 0.0288 (15), corresponding in total to 0.115 of an $\mathrm{O}$ atom. In view of this, the SQUEEZE option in PLATON was applied, and the final refinement utilized data so treated. The final $F_{o} / F_{c}$ CIF was produced with the CALC FCF option in PLATON, reporting both the original observed structure factors and calculated structure factors including the disordered solvent contribution.

Data collection: COLLECT (Hooft, 1999); cell refinement: DENZO (Otwinowski \& Minor, 1997) and COLLECT; data reduction: DENZO and COLLECT; program(s) used to solve structure: OSCAIL (McArdle, 2003) and SHELXS97 (Sheldrick, 1997); program(s) used to refine structure: OSCAIL and SHELXL97 (Sheldrick, 1997); molecular graphics: PLATON (Spek, 2003); software used to prepare material for publication: SHELXL97 and PRPKAPPA (Ferguson, 1999).
The X-ray data were collected at the EPSRC X-ray Crystallographic Service, University of Southampton; the authors thank the staff for all their help and advice. JLW thanks CNPq and FAPERJ for financial support.

Supplementary data for this paper are available from the IUCr electronic archives (Reference: SK1857). Services for accessing these data are described at the back of the journal.

\section{References}

Bowes, K. F., Ferguson, G., Glidewell, C., Lough, A. J., Low, J. N. \& Zakaria, C. M. (2002). Acta Cryst. C58, o347-o350.

Bowes, K. F., Ferguson, G., Glidewell, C., Low, J. N. \& Quesada, A. (2002). Acta Cryst. C58, o551-0554.

Cannon, D., Glidewell, C., Low, J. N., Quesada, A. \& Wardell, J. L. (2001). Acta Cryst. C57, 216-221.

Coupar, P. I., Ferguson, G. \& Glidewell, C. (1996). Acta Cryst. C52, 3052-3055.

Farrell, D. M. M., Glidewell, C., Low, J. N., Skakle, J. M. S. \& Zakaria, C. M. (2002). Acta Cryst. B58, 289-299.

Ferguson, G. (1999). PRPKAPPA. University of Guelph, Canada.

Ferguson, G., Glidewell, C., Low, J. N., Skakle, J. M. S. \& Wardell, J. L. (2001). Acta Cryst. C57, 315-316.

Glidewell, C., Cannon, D., Quesada, A., Low, J. N., McWilliam, S. A., Skakle, J. M. S. \& Wardell, J. L. (2001). Acta Cryst. C57, 455-458.

Glidewell, C., Low, J. N., McWilliam, S. A., Skakle, J. M. S. \& Wardell, J. L. (2002). Acta Cryst. C58, o100-o102.

Glidewell, C., Low, J. N., Skakle, J. M. S. \& Wardell, J. L. (2004). Acta Cryst. C60, o35-037.

Hooft, R. W. W. (1999). COLLECT. Nonius BV, Delft, The Netherlands.

McArdle, P. (2003). OSCAIL for Windows. Version 10. Crystallography Centre, Chemistry Department, NUI Galway, Ireland.

Otwinowski, Z. \& Minor, W. (1997). Methods in Enzymology, Vol. 276, Macromolecular Crystallography, Part A, edited by C. W. Carter Jr \& R. M. Sweet, pp. 307-326. New York: Academic Press.

Sheldrick, G. M. (1997). SHELXS97 and SHELXL97. University of Göttingen, Germany.

Sheldrick, G. M. (2003). SADABS. Version 2.10. University of Göttingen, Germany.

Skakle, J. M. S., Wardell, J. L., Low, J. N. \& Glidewell, C. (2001). Acta Cryst. C57, 742-746.

Spek, A. L. (2003). J. Appl. Cryst. 36, 7-13.

Tonogaki, M., Kawata, T., Ohba, S., Iwata, Y. \& Shibuya, I. (1993). Acta Cryst. B49, 1031-1039. 